\title{
Antioxidant Activity, Antiproliferation of Colon Cancer Cells, and Chemical Composition of Grape Pomace*
}

\author{
John W. Parry ${ }^{1 \# * *}$, Haiwen Li ${ }^{1 \#}$, Jia-Ren Liu ${ }^{1}$, Kequan Zhou ${ }^{2}$, Lei Zhang ${ }^{3}$, Shuxin Ren ${ }^{1}$ \\ ${ }^{1}$ Agricultural Research Station, Virginia State University, Petersburg, USA; ${ }^{2}$ Department of Nutrition and Food Science, Wayne \\ State University, Detroit, USA; ${ }^{3}$ College of Food Science, Biotechnology and Environmental Engineering, Zhejiang Gongshang \\ University, Hangzhou, China. \\ Email: **jparry@vsu.edu
}

Received April 23 $3^{\text {rd }}, 2011$; revised June $9^{\text {th }}$, 2011; accepted June $13^{\text {th }}, 2011$.

\begin{abstract}
Chardonnay and Tinta Cao grape pomaces were generated by the winemaking process. The pomaces were extracted with $50 \%$ acetone and tested for antioxidant capacities using the oxygen radical absorbance capacity (ORAC) assay, $D P P H_{E C 50}^{\circ}$, and $A B T S^{++}$scavenging capacity tests. Cytotoxicity and antiproliferative activities against Caco-2 and HT-29 human colon cancer cell lines were also analyzed. The quantitative detection of caspase-3 activity during the early apoptotic process was evaluated by fluorometric immunosorbent enzyme assay (FIENA). Induction of late stage apoptosis was analyzed by DNA fragmentation. Total phenolic content (TPC), individual phenolic acids, total oil, and fatty acid profile were also analyzed. The Tinta Cao pomace had the highest antioxidant capacity in all tests with an

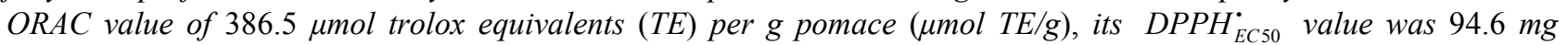
equivalents $/ L$, and its $A B T S^{++}$value was $806.7 \mu \mathrm{mol} T E / g$, which was more than twice as high as the Chardonnay. Both Tinta Cao and Chardonnay grape pomace extracts appear to contain components that inhibit the proliferation of Caco-2 and HT-29 cancer cells, at least in part, by triggering apoptosis. Expression of caspase-3 was induced by Tinta Cao and Chardonnay pomace extracts at $3 \mathrm{~g} / \mathrm{L}$ after 4 hours of treatment with a $308 \%$ and $229 \%$ increase compared to control, respectively. An increase in DNA fragmentation was also observed with both grape pomace treatments. This study demonstrated that these tested grape pomaces were potent scavengers of free radicals and may provide some level of protection against certain cancers.
\end{abstract}

Keywords: Grape Pomace, Antioxidant, Free Radical Scavenging, ORAC, DPPH, HT-29, Caco-2, Apoptosis, DNA Fragmentation, Caspase-3, TPC

\section{Introduction}

Over 7 million tons of grapes were harvested in the U.S. in 2009 (http://usda.mannlib.cornell.edu/usda/), and more than $60 \%$ were used to make wine or juice. Grape pomace is the main byproduct of wine and juice production and is primarily composed of skin, seed, pericarp, stem, and leaf among other components. Grape pomace is currently used as fodder, fertilizer, or it may be thrown away at a cost.

Biological free radicals include reactive oxygen spe-

\footnotetext{
*This project was funded solely by the USDA, CSREES (NIFA) Evans-Allen Program.

\#Authors have contributed equally to this work.
}

cies (ROS) such as the hydroxyl radical $\left(\mathrm{OH}^{\circ}\right)$, superoxide radical $\left(\mathrm{O}_{2}^{-}\right)$, peroxyl radical $\left(\mathrm{OOH}^{+}\right)$, and reactive nitrogen species (NOS) such as peroxynitrite $\left(\mathrm{ONOO}^{-}\right)$, peroxynitrous acid $(\mathrm{ONOOH})$, and nitric oxide $\left(\mathrm{NO}^{\circ}\right)$. Free radical inducers include transition metals such as iron III which can oxidize peroxides to produce $\mathrm{OH}^{*}$ through the Fenton reaction. These biological free radicals may damage DNA, protein, and lipids [1-3], and it is currently believed that they are among the underlying pathophysiological causes of the development of cancer, heart disease, aging, and other chronic health afflictions [4-6]. Antioxidants are free radical scavengers that can decrease radical induced detrimental effects [7-9].

Phytochemicals include phenolic compounds and are 
found in fruits and vegetables. Many of these compounds have been shown to have potent antioxidant activities and include phenolic acids such as gallic acid, ferulic acid, chlorogenic acid, and tocopherols among many others. There is a growing demand for the use of natural antioxidants as alternatives to synthetic antioxidant compounds such as BHA, BHT, or TBHQ due to their safety concern. Grape pomace is rich in antioxidant phytochemicals including phenolic compounds. The phytochemical profiles of different varieties of grape seeds have been documented, and significant antioxidant activity has been observed from pomace and seed flour extract $[10,11]$.

Studies suggest that grape seed extract may be useful for the prevention of certain cancers including prostate, leukemia, breast, skin and colon cancers [11-17] by decreasing cell proliferation, arresting cell cycle, inducing apoptosis, and interfering with intracellular signal transduction events [1]. Antioxidant components in foods are also beneficial in the protection against cardiovascular disease, and they possess other important properties including anti-radiation, anti-mutagenic, anti-inflammatory, antibacterial, and other beneficial effects $[7,8,18,19]$. The antioxidant compounds in grape are primarily found in the grape skin and seeds which are the primary components in the pomace.

Colorectal cancer is the cause of more than $1 / 2$ million deaths worldwide (World Health Organization 2006) [20], and it was ranked as the third leading cause of cancer-related death after lung cancer and stomach cancer. Epidemiological studies have shown strong evidence that diet and lifestyle play an important role in preventing cancer. In particular, an increased consumption of fruits and vegetables is associated with a decrease in cancer onset and mortality [21-27], thus, an intake of 5 or more servings of fruits and vegetables in one's daily diet was recommended by the American Cancer Society as a strategy for preventing cancer [28]. Grape byproducts are currently used as health beneficial nutraceutical products.

Apoptosis, known as programmed cell death, is involved in the regulation of physical development and also in cell homeostasis. There has been much recent study on apoptotic events by developmental and neurological biologists, immunologists, and other biological scientists, and there has been tremendous progress made to unveil the relationship between the apoptosis and antiproliferation of cancer cells.

Recently, grape seed extracts have been reported to have chemopreventive effects against intestinal and colorectal cancers in vivo and in vitro. The anti-cancer effects of grape seed extracts against colon cancer cells have also been demonstrated through the mechanisms involving apoptosis induction and the inhibition of the survival pathway [29-32].

In the current study, we investigated 2 grape species (Vitis vinifera) Tinta Cao (red) and Chardonnay (white) grape pomaces for antioxidant activities, inhibition of the proliferation of HT-29 and Caco-2 colon cancer cells, and phytochemical compositions. Antioxidant activities were determined using the oxygen radical absorption capacity (ORAC) assay along with $\mathrm{DPPH}^{*}$ and $\mathrm{ABTS}^{\circ+}$ scavenging capacities. In vitro cytotoxicity and antiproliferative effects against the 2 cancer cell lines were evaluated using the methylene blue cell counting method. Apoptotic activity was determined by testing for caspase-3 activity and DNA fragmentation. These tests were used to determine a possible mechanism for antiproliferation. Also, phytochemical compositions including total phenolic content (TPC), individual phenolic acids, total oil, and fatty acid profiles were studied.

\section{Materials and Methods}

\subsection{Materials}

Grape pomace samples were obtained from local Virginia growers. Chardonnay (white) grape pomace (nonfermented) was obtained from White Hall Vineyards in 2007, and Tinta Cao (red) grape pomace (fermented for 2 weeks) was obtained from Chrysalis Vineyards in 2007.

Gallic acid, ethylenediaminetetraacetate (EDTA), diphenyl-1-picrylhydrazyl radical (DPPH'), sodium acetate, potassium chloride, methylene blue, glutaraldehyde, acetic acid, and Trolox (6-hydroxy-2,5,7,8-tetramethylchroman-2-carboxylic acid) were purchased from SigmaAldrich (St. Louis, MO). 2,2'-azobis(2-amino- propane) dihydrochloride (AAPH) was obtained from Wako Chemicals USA (Richmond, VA). Disposable cell culture ware was purchased from Corning Glass Works (Corning, NY). Minimal Essential Medium (MEM), McCoy's 5A Medium Modified with L-glutamine, antibiotic/antimycotic, fetal bovine serum (FBS), $0.25 \%$ trypsin with 0.9 mM EDTA were purchased from Invitrogen (Carlsbad, CA). HT-29 and Caco-2 cell lines were purchased from American Type Culture Collection (Rockville, MD). Acetonitrile was obtained from G. J. Chemical Co. (Newark, NJ). Methanol was purchased through Fisher Scientific (Fair Lawn, NJ). Dioxane was obtained from Spectrum, (New Brunswick, NJ). Fatty acid methyl ester standards were purchased from Nu-Chek Prep Inc. (Elysian, MN) and included GLC-85 mixture. All other chemicals and solvents were of the highest commercial grade and used without further purification.

\subsection{Sample Preparation and Extractions}

Chardonnay and Tinta Cao grape pomace samples were air dried under low pressure. Dried pomace samples were 
milled to 40 mesh size using a Scienceware Bel Art Micromill, (Pequannock, NJ). The milled grape pomace samples were extracted with $50 \%$ acetone and evaluated for the ORAC assay, $\mathrm{DPPH}^{*}$ scavenging capacity, $\mathrm{ABTS}^{+}$ scavenging activity, and TPC. For cell cytotoxicity and growth inhibition, the $50 \%$ acetone extracts were evaporated, and the residual solids were re-dissolved in 50\% DMSO. The final concentration was $1 \mathrm{~g}$ pomace equivalent per $2 \mathrm{~mL}$ solvent. Individual phenolic acids were extracted with acetone/methanol/water $(7: 7: 6, \mathrm{v} / \mathrm{v} / \mathrm{v})$. Non-polar compounds in the pomace were extracted with hexane using a Soxhlet apparatus and were measured for total oil and fatty acid profiles. All samples were stored in the dark under nitrogen until analyzed.

\subsection{Oxygen Radical Absorbance Capacity (ORAC)}

ORAC values for the $50 \%$ acetone extracts of pomace samples were examined using 96 well plates with a Victor $^{3}$ V 1420 multilabel plate reader (PerkinElmer, Turku, Finland) following a previously described method with slight modification [33]. The temperature of the plate reader was maintained at $37^{\circ} \mathrm{C}$. Fluorescein was used as the fluorescent probe. The reaction solution contained $0.093 \mu \mathrm{M}$ fluorescein and $60 \mathrm{mM}$ AAPH final concentrations. First, $200 \mu \mathrm{L}$ of $75 \mathrm{mM}$ phosphate buffer $(\mathrm{pH}$ 7.4) was added to the wells, followed by $20 \mu \mathrm{L}$ reagent blank, standard, or pomace extract, then $20 \mu \mathrm{L}$ AAPH was added to start the reaction. Fluorescence measurements were recorded at $485 \mathrm{~nm}$ excitation $535 \mathrm{~nm}$ emission every minute for $40 \mathrm{~min}$. The area under the curve of fluorescence vs. time plot was calculated and compared against a standard curve prepared with Trolox. ORAC value was expressed as $\mu$ mol trolox equivalents (TE) per g pomace (TE $\mu \mathrm{mol} / \mathrm{g}$ ). Experiments were conducted in triplicate.

\section{4. $\mathrm{DPPH}_{\mathrm{EC} 50}^{-}$Scavenging Capacity Assay}

The $\mathrm{DPPH}_{\mathrm{EC} 50}^{\circ}$ values of the $50 \%$ acetone extracts were obtained using a high throughput assay [34]. A Victor $^{3}$ V 1420 multilabel counter (PerkinElmer, Turku, Finland) was used for assay determination using 96 well plates. The reaction mixtures contained $100 \mu \mathrm{L} 0.2 \mathrm{mM}$ $\mathrm{DPPH}^{\circ}$ and $100 \mu \mathrm{L}$ standards, control, blank, or sample. Absorbance readings were determined at $510 \mathrm{~nm}$. The $\mathrm{DPPH}_{\mathrm{EC} 50}^{-}$was determined as the concentration that effectively reduced the amount of $\mathrm{DPPH}^{*}$ to $50 \%$ of its original concentration following $10 \mathrm{~min}$ of reaction. Measurements were conducted in triplicate.

\subsection{ABTS $^{*+}$ Scavenging Capacity Assay}

The $\mathrm{ABTS}^{++}$scavenging capacity of the pomace extracts were evaluated according to previously reported protocol $[35,36]$. $\mathrm{ABTS}^{++}$was generated by oxidizing a $5 \mathrm{mM}$ aqueous solution of ABTS with manganese dioxide for $30 \mathrm{~min}$ at ambient temperature. The final reaction mixture contained $80 \mu \mathrm{L}$ of extract solution, standard or $50 \%$ acetone for control, and $1.0 \mathrm{~mL} \mathrm{ABTS}{ }^{++}$solution with an absorbance of 0.7 at $734 \mathrm{~nm}$. The absorbance at $734 \mathrm{~nm}$ was measured after a reaction time of $1 \mathrm{~min}$. Trolox equivalents (TE) were calculated using a standard curve and expressed in $\mu$ moles TE per g pomace ( $\mu \mathrm{mol} \mathrm{TE} / \mathrm{g})$.

\subsection{Cancer Cell Cytotoxicity and Antiproliferation}

Chardonnay and Tinta Cao grape pomace samples extracted using $50 \%$ acetone and were dried and then re-dissolved in 50\% DMSO. The 50\% DMSO solutions were then examined for cytotoxicity and antiproliferation on the HT-29 and Caco-2, human colon adenocarcinoma cell lines. HT-29 is a goblet type cell that excretes mucus upon differentiation, and Caco-2 is an absorptive type cell.

HT-29 and Caco-2 cells were propagated in T-75 flasks. HT-29 cell culture media included Mcoy's 5A media with $10 \%$ FBS and $1 \%$ antibiotic/antimycotic. Caco-2 cell culture media included Minimum Essential Media, $10 \%$ FBS, $1 \%$ antibiotic/antimycotic, $1 \%$ sodium pyruvate, and $0.5 \%$ nonessential amino acids. Cells were incubated at $37^{\circ} \mathrm{C}$ in a humidified atmosphere with $5 \%$ $\mathrm{CO}_{2}[11]$.

Cytotoxicity and antiproliferation were investigated using the methylene blue assay [37-39]. The test is based on the theory that methylene blue is absorbed into both live and dead cells but is not washed out with water in live cells, whereas, non-viable cells cannot retain methylene blue after washing. Absorbance was read at 570 $\mathrm{nm}$ and absorbance readings were directly correlated to live cell number. Briefly, media was removed from wells. The cells were stained with $60 \mu \mathrm{L}$ methylene blue solution $(1.25 \%$ glutaraldehyde, $0.6 \%$ methylene blue in HBSS without phenol red). Plates were then incubated at $37^{\circ} \mathrm{C}$ for $60 \mathrm{~min}$. Next, the wells were washed 4 times in distilled water by emersion. Cells were then destained by adding $100 \mu \mathrm{L}$ elution solution (50\% Ethanol and 1\% acetic acid in PBS) per well then shaken at room temperature for $30 \mathrm{~min}$. A Perkin Elmer Victor ${ }^{3}$ V 1420 multilabel counter (PerkinElmer, Turku, Finland) was used to measure absorbance. Measurements were taken in triplicate.

For the cytotoxicity tests, $5 \times 10^{4}$ cells were added to wells in 96 well plates then incubated for 24 hours. Cells were then treated with control or grape pomace extracts in $50 \%$ DMSO at $1.25,2.50$, and $5.00 \mathrm{~g} /$ pomace equivalents per L $(\mathrm{g}$ eq $/ \mathrm{L})$. All wells contained $0.5 \%$ DMSO. 
Following $24 \mathrm{~h}$ of exposure, wells were measured using the methylene blue assay. All tests were conducted in triplicate.

For antiproliferation, $2.5 \times 10^{4}$ cells were added to wells in 96 well plates and cultured as above. Cells were then treated with 0.31 to $2.50 \mathrm{~g}$ eq/ $\mathrm{L}$ and measured by the methylene blue assay following 72 and $96 \mathrm{~h}$. Triplicate measurements were taken. Effective concentration $\left(\mathrm{EC}_{50}\right)$ was determined after $96 \mathrm{~h}$ of treatment. $\mathrm{EC}_{50}$ was determined as the concentration of extract equivalents that had $50 \%$ of the cells compared to the control.

\subsection{Apoptosis Assays (Caspase-3 and DNA Fragmentation)}

HT-29 and Caco- 2 cells were seeded at $2 \times 10^{6}$ cells per well in 6-well culture plates and incubated at $37^{\circ} \mathrm{C}$ for 24 $\mathrm{h}$. The cells were then exposed to control or grape pomace extracts at 3.0 and $6.0 \mathrm{~g} \mathrm{eq} / \mathrm{L}$ for 4 and 12 hours for both apoptosis assays. The caspase- 3 analysis was used to determine early apoptosis, and the DNA fragmentation was used to determine late or final stage apoptosis. All treatments contained $0.5 \%$ DMSO.

For the caspase- 3 assay, cells were washed twice in ice-cold $1 \times$ PBS. Then caspase- 3 expression was detected as per the manufacturer's instructions by the fluorometric immunosorbent enzyme assay (FIENA) kit (Roche Applied Science, Mannheim, Germany). The fluorometric determination of proteolytic cleavage of the substrate of the samples was measured with a Victor $^{3} \mathrm{~V}$ 1420 multilabel plate reader (PerkinElmer, Turku, Finland) at excitation $425 \mathrm{~nm}$ and emission $490 \mathrm{~nm}$.

For the DNA fragmentation tests, DNA was extracted using the Apoptotic DNA Ladder Kit, (Roche Applied Science, Mannheim, Germany) with slightly modification. In brief, cells were washed twice with ice cold $1 \mathrm{x}$ PBS, then $200 \mathrm{uL}$ binding/lysis buffer was added and mixed immediately. After holding for $10 \mathrm{~min}$ at $22^{\circ} \mathrm{C}$, $100 \mu \mathrm{L}$ of $100 \%$ isopropanol was added and the solution was vortexed for $10 \mathrm{sec}$. The lysate was run through the column then washed twice with washing buffer. DNA was eluted with $200 \mu \mathrm{L}$ of pre-warmed $\left(70^{\circ} \mathrm{C}\right)$ elution buffer and concentrated with a speedvac. Extracted DNA was subjected to gel electrophoresis, and the image was captured with UVP EC3 bioimaging system (Upland, CA).

\subsection{Total Phenolic Content (TPC)}

TPC of the pomace extracts was determined using Folin and Ciocalteu's (FC) reagent following a previously described method [40]. The FC reagent was freshly prepared, and the final reaction mixture contained $250 \mu \mathrm{L}$ of the FC reagent, $750 \mu \mathrm{L} 20 \% \mathrm{Na}_{2} \mathrm{CO}_{3}, 50 \mu \mathrm{L}$ of pomace extract or standard, and $3 \mathrm{~mL} \mathrm{H}_{2} \mathrm{O}$. Absorbance was de- termined at $765 \mathrm{~nm}$ following 2 hours of reaction at ambient temperature. Gallic acid was used as the standard. Measurements were taken in triplicate.

\subsection{Individual Phenolic Acids}

The soluble and insoluble phenolic acid compositions of pomace samples were determined according to the method by Moore et al., [33] with some modifications. The soluble phenolic acids in the pomace samples were extracted with acetone/methanol/water $(7: 7: 6, \mathrm{v} / \mathrm{v} / \mathrm{v})$, after organic solvents were evaporated under nitrogen, the extractions were further hydrolyzed with $2 \mathrm{~N} \mathrm{NaOH}$ for 4 hours at $45^{\circ} \mathrm{C}$. The resulting mixture was acidified with $6 \mathrm{~N} \mathrm{HCl}$ and was subsequently extracted with ethyl acetate and ethyl ether $(1: 1, \mathrm{v} / \mathrm{v})$. The organic phase was collected and dried using a nitrogen evaporator (Labconco, Missouri). The residue was re-dissolved in methanol and remaining solids were removed using a 0.45 $\mu \mathrm{m}$ filter. The filtrate was stored at $-20^{\circ} \mathrm{C}$ under nitrogen for HPLC analysis. For the insoluble bound phenolic acids, the resulting residues were hydrolyzed with $2 \mathrm{~N}$ $\mathrm{NaOH}$ under nitrogen for 12 hours. After hydrolysis, the mixtures were centrifuged and the supernatant was acidified. The subsequent purifications were prepared as the soluble phenolic acids.

HPLC analysis was performed on an Agilent 1200 quaternary LC system (Agilent Technologies, CA) equipped with a photodiode array detector. Phenolic acids were separated on a Phenomenex Luna $5 \mu$ C18 column $(250 \mathrm{~mm} \times 4.6 \mathrm{~mm})$ using a mobile phase containing solvent A (acetic acid $/ \mathrm{H}_{2} \mathrm{O}, 2: 98, \mathrm{v} / \mathrm{v}$ ) and solvent $\mathrm{B}$ (acetic acid/acetonitrile/ $\mathrm{H}_{2} \mathrm{O}, 2: 30: 68, \mathrm{v} / \mathrm{v} / \mathrm{v}$ ). The solvent gradient was linear from 10 to $100 \%$ solvent B for 42 min with a flow rate of $1.0 \mathrm{~mL} / \mathrm{min}$. Phenolic acids were identified by comparing the retention time and absorption spectra of peaks in the samples to those of the individual standard compounds. Quantification was conducted using total area under each peak compared to external standards. Samples were measured in duplicate.

\subsection{Fatty Acid Composition}

Fatty acid methyl esters (FAME) were prepared from the hexane extracted oils using the previously described method [41]. Fatty acid compositions were analyzed using an Agilent $6890 \mathrm{~N}$ HP-GC with a FID. The column was a Supelco $2340(60 \mathrm{~m} \times 0.25 \mathrm{~mm}$ i.d. $0.20 \mu \mathrm{m}$ film thickness (Supelco Inc., Bellefonte, PA). Helium was the carrier gas at a flow rate of $0.8 \mathrm{~mL} / \mathrm{min}$, a linear velocity $18 \mathrm{~cm} / \mathrm{s}$ and a split ratio of $100: 1$. The injection volume was $2 \mu \mathrm{L}$. The injector temperature was set at $240^{\circ} \mathrm{C}$ and the detector at $280^{\circ} \mathrm{C}$. Time and temperature ramps began with an initial oven temperature of $100^{\circ} \mathrm{C}$ for $3 \mathrm{~min}$ then $3^{\circ} \mathrm{C}$ to $240^{\circ} \mathrm{C}$, followed by isothermal for $15 \mathrm{~min}$. Fatty 
acids were determined by comparing GC retention time with that of the authorized pure individual commercial compounds.

\subsection{Statistical Analysis}

Data was analyzed using SPSS (SPSS for Windows, Version Rel. 10.0.5., 1999, SPSS Inc., Chicago, IL). Data were reported as mean \pm standard deviation $(n=3)$. Analysis of variance and Tukey's post hoc analysis was used to determine differences among means. Pearson Correlation Coefficient was used to determine correlations among means. Significance was declared at $P<$ 0.05 .

\section{Results and Discussion}

\subsection{Oxygen Radical Absorbance Capacity (ORAC)}

Antioxidant activities of the grape pomace extracts were estimated using the ORAC assay (Table 1). Both of the grape pomace extracts demonstrated significant radical scavenging activities. The ORAC values of the pomace extracts were 331.1 and $386.4 \mathrm{TE} \mu \mathrm{mol} / \mathrm{g}$ for Chardonnay and Tinta Cao grape extracts, respectively (Table 1). In a previous study, Chardonnay grape seed flour was compared to several other flour sources using the ORAC method extracted with 50\% acetone including Pinot Noir grape seed flour, which is a red grape seed flour. The ORAC value of the Chardonnay seed flour was significantly higher than all other samples including Pinot Noir sample. The results showed that the Chardonnay seed flour extract had an ORAC value of $1076 \mathrm{TE} \mu \mathrm{mol} / \mathrm{g}$ while the Pinot Noir seed flour extract had an ORAC value of approximately $313 \mathrm{TE} \mu \mathrm{mol} / \mathrm{g}$ [11].

\section{2. $\mathrm{DPPH}_{\mathrm{EC} 50}^{\cdot}$ Scavenging Capacity Assay}

Antioxidant activity using $\mathrm{DPPH}^{\circ}$ was evaluated using $\mathrm{DPPH}_{\mathrm{EC} 50}$ method (Table 1). The $\mathrm{DPPH}_{\mathrm{EC} 50}$ is the concentration of an extract that can reduce the concentration of $\mathrm{DPPH}^{*}$ to $50 \%$ of the original concentration at a selected time point. We used $10 \mathrm{~min}$. The Tinta Cao pomace extract showed a stronger reducing capacity than the Chardonnay pomace extract with an $\mathrm{EC}_{50}$ value of $94.6 \mathrm{mg}$ pomace equivalents per $\mathrm{L}(\mathrm{mg} \mathrm{eq} / \mathrm{L})$, while the Chardonnay had an $\mathrm{EC}_{50}$ value of $154.2 \mathrm{mg}$ eq/L. In a 2008 study by Llobera and Canellas [42], Prensal Blanc grape pomace and stem were tested for their $\mathrm{DPPH}_{\mathrm{EC} 50}$ values. The results showed that the stem had a higher antioxidant capacity than the pomace. The $\mathrm{DPPH}_{\mathrm{EC} 50}$ values were 0.79 , and $1.32 \mathrm{~g}$ dry matter per $\mathrm{g} \mathrm{DPPH}$, respectively. In another study, Chardonnay grape (white) and Pinot Noir (red) seed flours were extracted with 50\% acetone and tested for $\mathrm{DPPH}_{\mathrm{EC} 50}$. The Chardonnay flour extract had a $\mathrm{DPPH}_{\mathrm{EC} 50}$ value of $39 \mathrm{mg}$ eq/L, while the Pinot Noir flour extract had a value of $160 \mathrm{mg}$ eq/L [11].

\subsection{ABTS $^{\circ+}$ Scavenging Capacity Assay}

$\mathrm{ABTS}^{\circ+}$ scavenging capacity was analyzed using Trolox as the standard. Values were 393.6 and $806.7 \mathrm{TE} \mu \mathrm{mol} / \mathrm{g}$ in the Chardonnay and Tinta Cao grape pomace extracts, respectively (Table 1). The Tinta Cao sample value was more than twice as high compared to the Chardonay.

The results from the analyses of these 3 common antioxidant capacity assays: ORAC, DPPH'and, $\mathrm{ABTS}^{++}$, showed that the Tinta Cao (red) grape pomace extract had a significantly higher antioxidant capacity than Chardonnay (white) grape pomace extract. This is not in support of previous data in which Chardonnay seed flour extract was significantly higher in antioxidant capacity compared to Pinot Noir (Vitis vinifera) seed flour, which is a red grape [11]. The differences in the ORAC, DPPH', and $\mathrm{ABTS}^{\text {s+ }}$ values of the current and previous studies of Chardonnay seeds indicate that the grape seed may contain more antioxidant compounds than the grape skin [11, 43]. The Chardonnay grape seed from the current study comprised $35.4 \%$ of the pomace weight while the seed weight of the Tinta Cao pomace was $47.1 \mathrm{~g} / 100 \mathrm{~g}$ pomace, which is $11.7 \%$ more seed per pomace weight. Also, the Chardonnay seed flour extract from the previous study (11) was cold-pressed, which removed most of the oil, and seed oils have been shown to have lower antioxidant values compared to seed flours $(11,43)$.

There are many possible affecters of antioxidant and phenolic content which include amounts of sunlight,

Table 1. Antioxidant activities of grape pomace samples.

\begin{tabular}{|c|c|c|c|c|}
\hline Pomace Sample & ${ }^{\mathrm{a}} \mathrm{ORAC}(\mu \mathrm{mol} \mathrm{TE} / \mathrm{g})$ & ${ }^{\mathrm{b}} \mathrm{ABTS}^{++}(\mu \mathrm{mol} \mathrm{TE} / \mathrm{g})$ & ${ }^{\mathrm{c}} \mathrm{DPPH}_{\mathrm{EC} 50} 10 \mathrm{~min} \mathrm{mg} \mathrm{eq} / \mathrm{L}$ & TPC GAE mg/g \\
\hline Chardonnay Grape & $331.1 \mathrm{~b} \pm 6.0$ & $393.6 \mathrm{~b} \pm 7.2$ & $154.2 \mathrm{~b} \pm 2.2$ & $47.7 b \pm 4.4$ \\
\hline Tinta Cao Grape & $386.4 \mathrm{a} \pm 8.3$ & $806.7 \mathrm{a} \pm 12.2$ & $94.6 \mathrm{a} \pm 12.0$ & $72.0 \mathrm{a} \pm 3.0$ \\
\hline
\end{tabular}

${ }^{\mathrm{a} O R A C}$ is the oxygen radical absorbance capacity measured as micromoles of Trolox equivalents (TE) per gram pomace $(\mu \mathrm{mol} \mathrm{TE} / \mathrm{g})$; ${ }^{\mathrm{b}} \mathrm{ABTS}{ }^{\circ+}$ radical scavenging was measured as $(\mu \mathrm{mol} \mathrm{TE} / \mathrm{g}) ;{ }^{\mathrm{c}} \mathrm{DPPH}{ }^{*}$ scavenging capacity was analyzed for its inhibitory concentration $\left(\mathrm{DPPH}_{\mathrm{EC} 50)}\right)$ which is the concentration of sample that can reduce the percent of DPPH to $1 / 2$ of its original concentration at a selected time $(10 \mathrm{~min})$. DPPH measurements are defined as mg pomace equivalents per $\mathrm{L}(\mathrm{mg}$ eq/L). Values in the same column with different letters are significantly different $(P<0.05)$. TPC values are defined as the $\mathrm{mg}$ gallic acid equivalents per gram pomace $(\mathrm{GAE} \mathrm{mg} / \mathrm{g})$. 
pollution, water, and infestation by insects, bacteria, and fungus, among others.

\subsection{Cell Cytotoxicity and Antiproliferation}

The $50 \%$ acetone grape extracts were evaporated to solid and brought into $50 \%$ DMSO solutions for testing. Solutions were tested in the HT-29 and Caco-2 human colon cancer cell lines for cytotoxicity following $24 \mathrm{~h}$ and antiproliferation following 72 and $96 \mathrm{~h}$ treatment. The Tinta Cao extract had the highest cytotoxicity compared to the Chardonnay extract in both HT-29 and Caco-2 cells (Figures 1 and 2). The cytotoxicity from the Tinta Cao pomace extract in HT-29 cells was most potent at $1.25 \mathrm{~g}$ $\mathrm{eq} / \mathrm{L}(22.7 \%)$ and remained similar at 2.50 and $5.00 \mathrm{~g}$ eq/L. The cytotoxicity from the Chardonnay pomace extract on the HT-29 cell line was most potent at $2.50 \mathrm{~g}$ $\mathrm{eq} / \mathrm{L}$ at $23.6 \%$, which was slightly higher than the Tinta Cao extract (Figure 1). In the Caco-2 cell line, the Tinta Cao pomace extract also had the highest cytotoxicity values of $10.7 \%, 20.0 \%$, and $34.2 \%$ at $1.25,2.50$ and $5.00 \mathrm{~g} \mathrm{eq} / \mathrm{L}$, respectively (Figure 2). The Chardonnay pomace extract had cytotoxicity values of $1.6 \%, 11.5 \%$, and $28.1 \%$ at $1.25,2.50$, and $5.00 \mathrm{~g} \mathrm{eq} / \mathrm{L}$, respectively. Both Tinta Cao and Chardonnay pomace extracts showed dose-dependent responses to cytotoxicity in Caco-2 cells.

Antiproliferation effects from both Chardonnay and Tinta Cao grape pomace extracts on HT-29 and Caco-2 colon cancer cell lines were determined at 4 different concentrations (Figures 3 and 4). The results showed a dose-dependent inhibition of cell proliferation after 72 and $96 \mathrm{~h}$ of treatment compared to control from both grape pomace samples.

The proliferation of the HT-29 cells was significantly inhibited beginning at 0.62 and $1.25 \mathrm{~g}$ eq/L from the Tinta Cao and Chardonnay pomace extracts, respectively (Figure 3). In the HT-29 cells, the $\mathrm{EC}_{50}$ of both Tinta Cao and Chardonnay pomace extracts were determined. The $\mathrm{EC}_{50}$ is the concentration of extract in the cell media that causes a $50 \%$ lower cell count compared to control at a specified time period. After $96 \mathrm{~h}$ the $\mathrm{EC}_{50}$ of Tinta Cao extract was $1.00 \mathrm{~g}$ eq/L while the $\mathrm{EC}_{50}$ of the Chardonnay extract was $1.83 \mathrm{~g}$ eq/L.

The proliferation of the Caco- 2 cells was significantly inhibited by both grape pomace extracts at the lowest tested concentration of $0.31 \mathrm{~g} \mathrm{eq} / \mathrm{L}$ after 72 and $96 \mathrm{~h}$ of treatment (Figure 4). The $\mathrm{EC}_{50}$ of Tinta Cao extract was $0.82 \mathrm{~g} \mathrm{eq} / \mathrm{L}$, and the Chardonnay extract had an $\mathrm{EC}_{50}$ of $1.02 \mathrm{~g}$ eq $/ \mathrm{L}$ in the Caco-2 cell line. A possible reason that the Caco-2 cells were more susceptible to the pomace extracts than the HT-29 cells after 72 and $96 \mathrm{~h}$ of treatment is unclear. However, Caco- 2 cells, upon differentiation, act as endocrine cells, and HT-29 cells act as excretory cells. This suggests that the Caco-2 cells may absorb

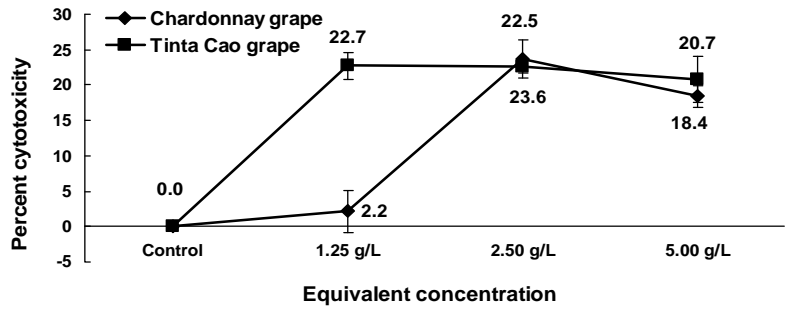

Figure 1. Cytotoxic effects of pomace extracts on HT-29 cells. Cells were treated with $1.25,2.50$, and $5.00 \mathrm{~g}$ pomace equivalents/L media and were counted following $24 \mathrm{~h}$ of treatment. Numbers indicated on the figure for Chardonnay are lower than the Tinta Cao numbers at specified concentrations.

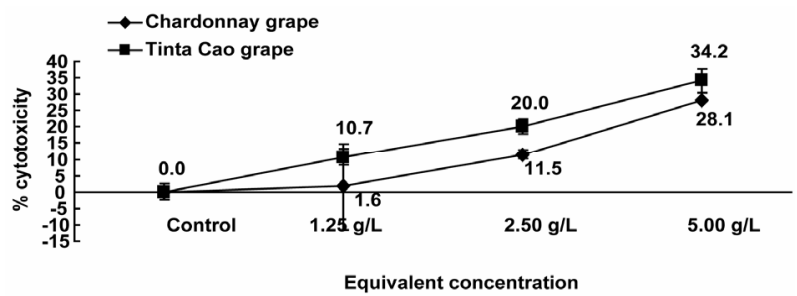

Figure 2. Cytotoxic effects of pomace extracts on Caco-2 cells. Cells were treated with $1.25,2.50$, and 5.00 g pomace equivalents/L media and were counted following $24 \mathrm{~h}$ of treatment.

more antiproliferative compounds from the extract than the HT-29 cells. This could partially explain the higher antiproliferative effect following 72 and $96 \mathrm{~h}$ of treatment. However, this is not case after $24 \mathrm{~h}$ of treatment in the cytotoxicity experiment (Figures $\mathbf{1}$ and 2). A possible reason for this is that the Caco-2 cells were not as adherent to the culture plates compared the HT-29 cells, and the chemical reactions in the Caco-2 cells were favored to becoming established on the surface of the plate compared to absorbing outside molecules during the first $24 \mathrm{~h}$ of treatment.

\subsection{Caspase-3 Expression}

Caspase-3 expression plays a key role in early stage apoptosis. Using an anti-caspase-3 specific monoclonal antibody together with a specific caspase substrate, caspase- 3 concentration was determined in the HT-29 colon cancer cells treated with Chardonnay and Tinta Cao grape pomace extracts by fluorometric immunosorbent enzyme assay (FIENA) (Figure 5). A significant increase in caspase- 3 expression was observed from both grape pomace extracts after $4 \mathrm{~h}$ at 3 and $6 \mathrm{~g}$ eq/L $(P<$ $0.05)$. HT-29 cells treated with $6 \mathrm{~g}$ eq/L Tinta Cao grape pomace extract showed the highest increase of caspase- 3 expression of $308.5 \%$ compared to control after $4 \mathrm{~h}$ of treatment, while the HT-29 cells treated with $6 \mathrm{~g}$ eq/L Chardonnay extract increased caspase- 3 expression by 


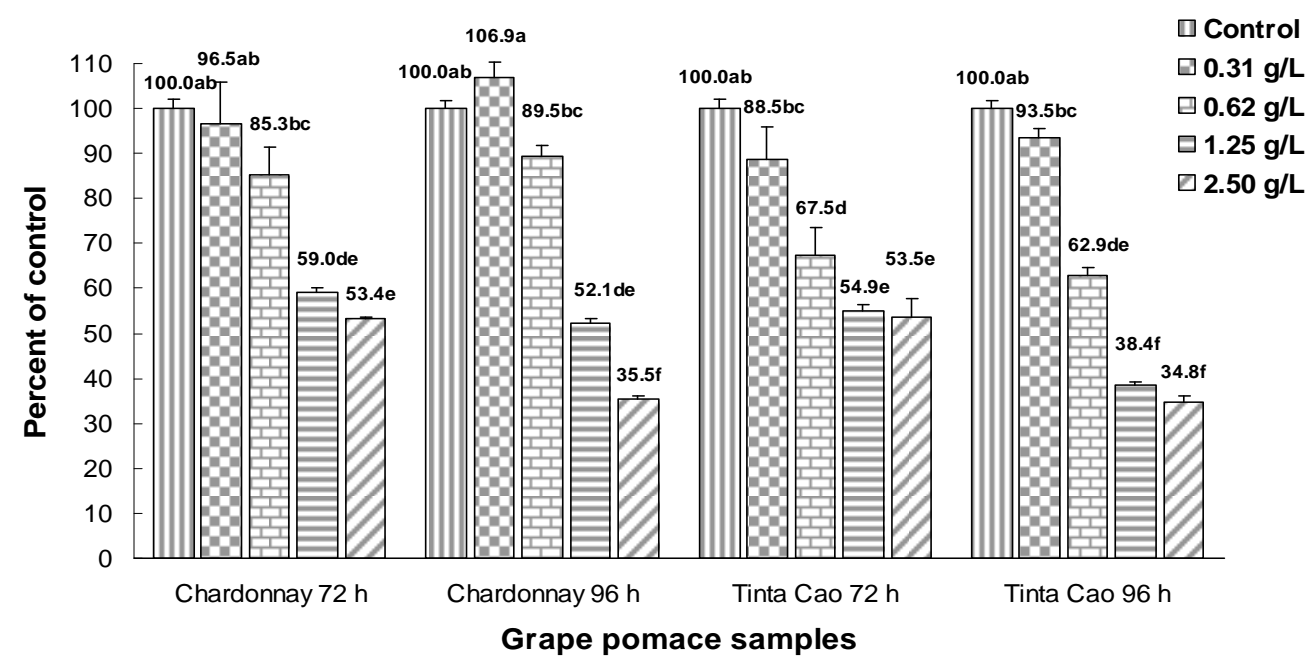

Figure 3. Effects of Chardonnay and Tinta Cao grape pomace extracts on proliferation of HT-29 colon cancer cells. Cells were treated with $0.31,0.62,1.25$, and 2.50 g pomace equivalents/L media and were counted following 72 and 96 h of treatment. Bars with different letters are significantly different $(P<0.05, n=3)$.

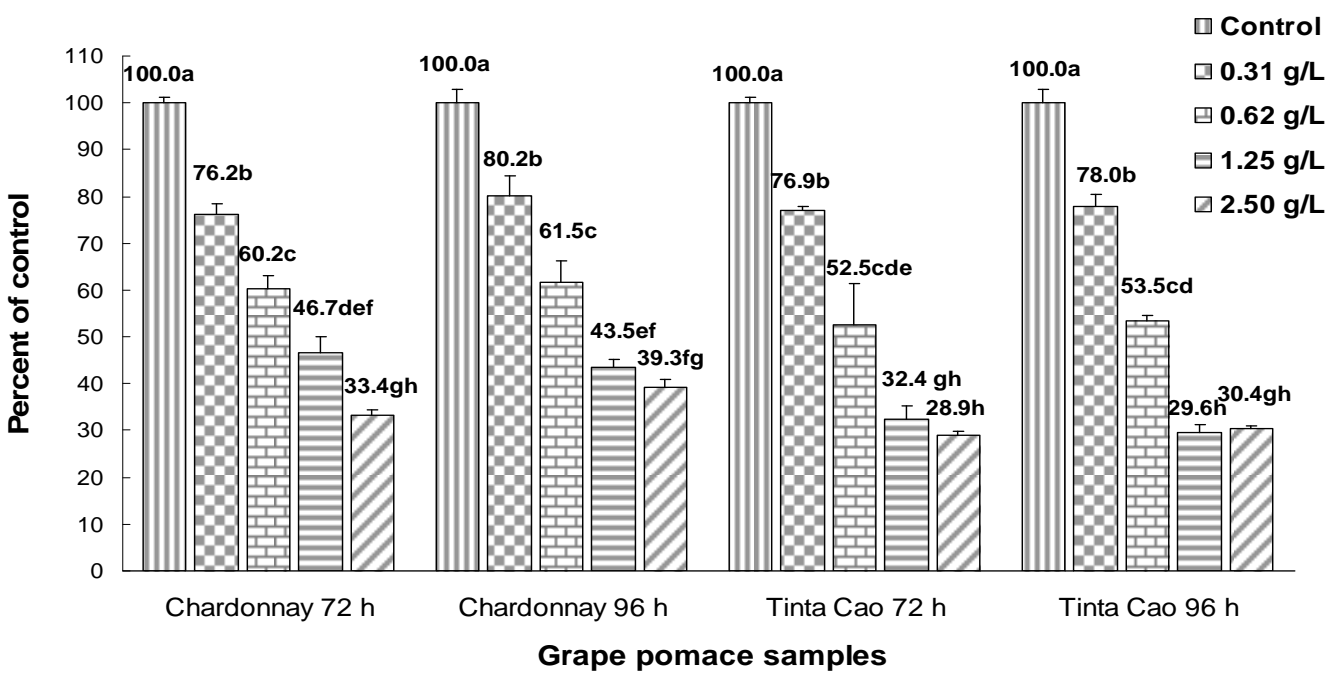

Figure 4. Effects of Chardonnay and Tinta Cao grape pomace extracts on proliferation of Caco-2 colon cancer cells. Cells were treated with $0.31,0.62,1.25$, and 2.50 g pomace equivalents/L media and were counted following 72 and 96 h of treatment. Bars with different letters are significantly different $(P<0.05, n=3)$.

228.8\%. The results presented in Figure 5 suggest that the components in the extract of Chardonnay and Tinta Cao grape pomaces induce caspase- 3 expression resulting in apoptosis in the HT-29 cells. Furthermore, Tinta Cao pomace may be a more potent inducer of apoptosis compared to Chardonnay based on the $4 \mathrm{~h}$ results. Following $12 \mathrm{~h}$ of treatment, caspase- 3 expression was significantly lower than the $4 \mathrm{~h}$ results suggesting that the compounds in the extract had an immediate effect in the induction of apoptosis.

\subsection{DNA Fragmentation}

DNA fragmentation is a marker of late stage apoptosis. It was used to support the caspase-3 expression test to identify apoptosis. Fragmentation was induced in both HT-29 and Caco-2 colon cancer cell lines after treatment with Chardonnay grape pomace extract using 3 and $6 \mathrm{~g}$ eq/L media (Figure 6). This figure demonstrates internucleosomal DNA degradation from gel electrophoresis of HT-29 colon cancer cells. A characteristic DNA ladder was observed when HT-29 colon cancer cells were treated with both 3 and $6 \mathrm{~g}$ eq/L of Chardonnay grape pomace extract after $4 \mathrm{~h}$ of treatment (Figure 6, lanes 4 \& 5), and no DNA ladder was shown from the untreated negative control (Figure 6, lane 3). Fragmented DNA was also observed in the HT-29 cells when treated with 3 


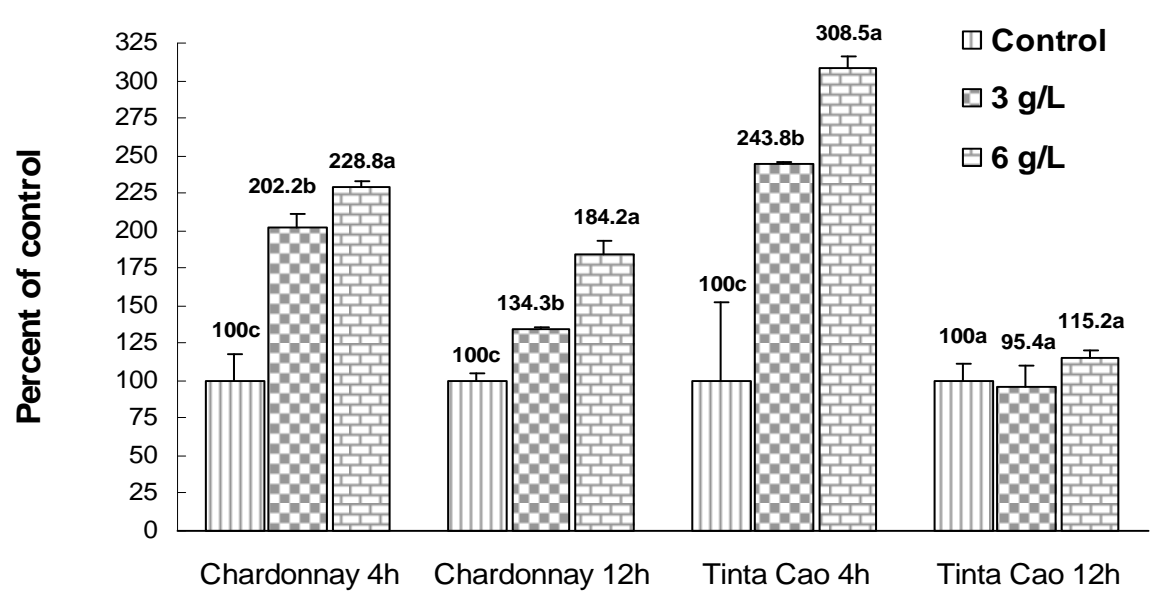

\section{Grape pomace samples}

Figure 5. Caspase-3 expression induced by Chardonnay and Tinta Cao grape pomace extracts in HT-29 cells after $4 \mathrm{~h}$ and $12 \mathrm{~h}$ of treated with 0.3 and $6.0 \mathrm{~g}$ eq/L. Bars with different letters within the separated treatment groups are significantly different $(P<0.05, n=3)$.

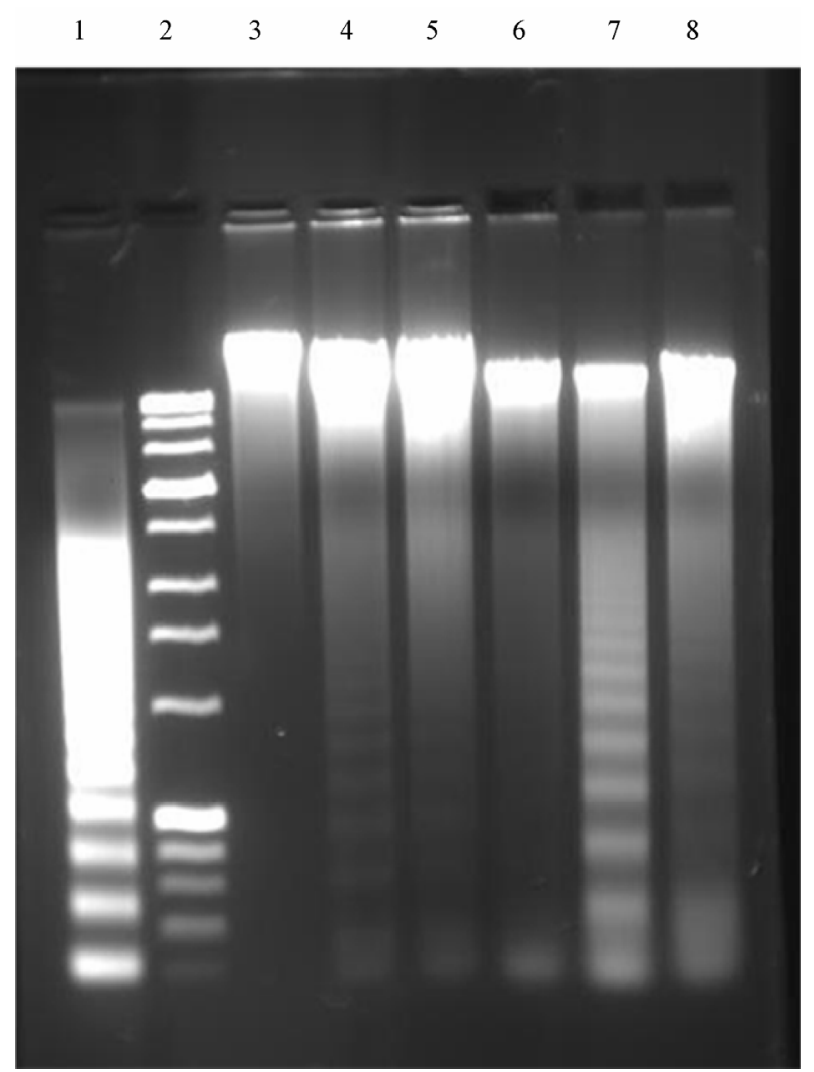

Figure 6. DNA fragmentation induced by Chardonnay grape pomace extracts in HT-29 cells after $4 \mathrm{~h}$ and $12 \mathrm{~h}$ treatment. Lane 1: positive control; Lane 2: molecular marker; Lane 3 - 5: cells treated with 0.3 and $6.0 \mathrm{~g}$ eq/L of Chardonnay grape pomace extract for 4 hours; Lane 6 - 8: cells treated with 0.3 and $6.0 \mathrm{~g} \mathrm{eq} / \mathrm{L}$ of Chardonnay grape pomace extract for 12 hours. and $6 \mathrm{~g}$ eq/L of Chardonnay grape pomace extract for 12 hours (Figure 6, lanes $7 \& 8$ ). No DNA ladder was shown from negative control cells (Figure 6, lane 6). The highest percentage of the apoptotic cells was ob- served in the HT-29 cell line treated with $3 \mathrm{~g}$ eq/L of Tinta Cao grape extract for 12 hours. Similar results were observed in 3 and $6 \mathrm{~g} \mathrm{eq} / \mathrm{L}$ of Chardonnay and Tinta Cao grape pomace extract treated Caco-2 cell line (data not shown).

Caspase 3 expression and DNA fragmentation are indicative of early and late stages of apoptosis, respectively. Recently, the importance of grape seed extract in inhibittion of cancer cell growth has been investigated $[15,44]$. The antiproliferation effect on the colon cancer cells in the present study are in agreement with the previous reports. The extracts in our present study are from grape pomace, which include skin, seed, pericarp, and stem of the fruit.

\subsection{Total Phenolic Content (TPC)}

The TPC values of the tested $50 \%$ acetone extracts are shown in (Table 1). The Tinta Cao pomace had a TPC value of $72.0 \mathrm{mg}$ gallic acid equivalents (GAE) per $\mathrm{g}$ pomace (GAE $\mathrm{mg} / \mathrm{g}$ ) and was significantly higher than the TPC value of the Chardonnay. Previous results from Chardonnay grape seed flours extracted with $50 \%$ acetone showed a TPC value of $186.3 \mathrm{GAE} \mathrm{mg} / \mathrm{g}$ while the flour of Pinot Noir (red) grape had a TPC value of 55.5 GAE mg/g (11). In a prior study by Campos and others [45], the TPC of Cabernet Sauvignon (red) pomace was examined using several non-polar solvent systems including supercritical fluid extraction, classical organic solvent extraction, and Soxhlet. The most water soluble 
solvent was ethanol, and it had the highest TPC value of $3.4 \mathrm{GAE} \mathrm{mg} / \mathrm{g}$. This suggests that the majority of antioxidant components in grape pomace are hydrophilic.

\subsection{Individual Phenolic Acids}

Individual phenolic acids have been shown to be potent antioxidants and major contributors to the overall antioxidant activities of foods. Their antioxidant activity is a result of their radical resonance stability of the electrons in the benzene ring with the attached hydroxyl and carboxylate groups. Tinta Cao grape had the highest concentration of phenolic acids at $236.8 \mu \mathrm{g} / \mathrm{g}$ pomace, which was 5.5 -fold higher compared to the Chardonnay grape pomace extract (Table 2). The Tinta Cao was primarily composed of chlorogenic acid $(110.2 \mu \mathrm{g} / \mathrm{g})$. The Chardonnay grape pomace contained p-coumaric acid as $1 / 3$ of its total phenolic acids. (Table 2). Gallic acid, which is commonly used as the standard for the TPC tests, was found highest in the Tinta Cao at $8.4 \mu \mathrm{g} / \mathrm{g}$.

\subsection{Fatty Acid Composition}

The pomace oils from grape samples that were extracted using a Soxhlet apparatus with hexane were analyzed for total oil and fatty acid (FA) profile. The highest total oil content was found in the Tinta Cao grape pomace at 12.5 $\mathrm{g}$ oil/100 g pomace, (Table 3). The pomace oils had relatively high levels of linoleic acid (18:2) and oleic acid (18:1). Levels of 18:2 and 18:1 were 68.7 and $19.4 \mathrm{~g} / 100$ g FA in the Chardonnay pomace, respectively, and 18:2 and $18: 1$ were 68.7 and $72.3 \mathrm{~g} / 100 \mathrm{~g}$ FA, respectively. Tinta Cao grape pomace oil had the highest percent of 18:2 (Table 3). Both pomace oils had very high levels of unsaturated fatty acids. Tinta Cao pomace oil had 90.5 g/100 g FA, and Chardonnay pomace oil had 88.5 g/100 g FA. Grape seed fatty acid composition has been studied extensively, and has been shown to primarily contain linoleic acid from approximately 50 to $78 \%$ of the total fatty acids. The grape seed oil also contains a significant level of oleic acid from about 14 to $32 \%$ of the total fatty acids [46,47].

\section{Conclusions}

The main objective of present study was to evaluate Chardonnay and Tinta Cao grape pomaces for antioxidant activity, antiproliferation of 2 colon cancer cell lines, and chemical compositions. The current study demonstrated that grape pomace extracts are potent scavengers of free radicals and inhibit cancer cell proliferation, at least, through the induction of apoptosis. The results suggest that grape pomace has the potential to be a bioactive food ingredient and increase the profits for grape growers as a value-adding byproduct of wine and juice production. Further investigation of the 2 grape
Table 2. Phenolic acid composition of tested pomaces.*

\begin{tabular}{ccc}
\hline Phenolic acid $(\mu \mathrm{g} / \mathrm{g})$ & Chardonnay Grape & Tinta Cao Grape \\
\hline Gallic Acid & $3.1 \pm 0.6$ & $8.4 \pm 1.1$ \\
Gentisic Acid & $2.9 \pm 0.1$ & $5.0 \pm 0.3$ \\
4-OH Benzoic Acid & $2.3 \pm 0.1$ & $3.4 \pm 0.0$ \\
Chlorogenic Acid & $10.0 \pm 0.3$ & $110.2 \pm 6.7$ \\
Vanillic Acid & $4.9 \pm 1.5$ & $30.2 \pm 1.6$ \\
Caffeic Acid & $1.5 \pm .03$ & $17.4 \pm 0.3$ \\
p-Coumaric Acid & $15.5 \pm 5.9$ & $27.9 \pm 3.1$ \\
Ferulic Acid & $2.8 \pm 0.0$ & $34.3 \pm 2.2$ \\
Total $(\mu \mathrm{g} / \mathrm{g})$ & 43.0 & 236.8 \\
\hline
\end{tabular}

*Chardonnay grape and Tinta Cao grape represent their respective pomaces. Individual phenolic acids were compared to external standards and are measured as $\mu \mathrm{g} / \mathrm{g}$ pomace $(\mu \mathrm{g} / \mathrm{g})(n=2)$.

Table 3. Fatty acid (FA) profiles of the pomace samples (g/100 g FA) ${ }^{*}$ and total oil \% (g/100 g pomace).

\begin{tabular}{ccc}
\hline FA & Chardonnay Grape & Tinta Cao Grape \\
\hline $16: 0$ & $8.3 \pm 0.1$ & $7.9 \pm 0.2$ \\
$18: 0$ & $3.2 \pm 0.4$ & $1.6 \pm 0.0$ \\
$18: 1$ & $19.4 \pm 0.6$ & $18.3 \pm 0.2$ \\
$18: 2$ & $68.7 \pm 0.5$ & $72.3 \pm 0.5$ \\
$18: 3$ & $0.5 \pm 0.5$ & ND \\
$20: 1$ & ND & ND \\
SAT & 11.5 & 9.5 \\
MUFA & 19.4 & 18.3 \\
PUFA & 69.2 & 72.3 \\
Total Oil $\%$ & 8.1 & 12.5 \\
\hline
\end{tabular}

"SAT: saturated fatty acid, MUFA: monounsaturated fatty acids, PUFA: polyunsaturated fatty acids. SAT, MUFA, and PUFA were calculated using identified fatty acids. ND: not detected. Data were expressed as mean \pm SD $(n=3)$.

pomaces on possible food supplementary applications in health promotion and disease prevention for improving human nutrition is needed.

\section{Acknowledgments}

The authors gratefully acknowledge the financial support from USDA CSREES (NIFA) Evans-Allen Program. J. W.P., designed research; H.L., J-R.L; J.W.P., K.Z., L.Z., S.R., conducted research; H.L, J-R. L; J.W.P. analyzed data; H.L., J.W.P wrote manuscript; J.W.P. had primary responsibility for final content. All authors read and approved the final manuscript. 


\section{REFERENCES}

[1] S. U. Mertens-Talcott, J. H. Lee, S. S. Percival and S. T. Talcott, "Induction of Cell Death in Caco-2 Human Colon Carcinoma Cells by Ellagic Acid Rich Fractions from Muscadine Grapes (Vitis rotundifolia)," Journal of Agricultural and Food Chemistry, Vol. 54, No. 15, 2006, pp. 5336-5343. doi:10.1021/jf060563f

[2] J. D. Potter, "Cancer Prevention: Epidemiology and Experiment," Cancer Letters, Vol. 114, No. 1-2, 1997, pp. 7-9. doi:10.1016/S0304-3835(97)04615-6

[3] J. D. Potter, "Nutrition and Colorectal Cancer," Cancer Cause Control, Vol. 7, No. 1, 1996, pp. 127-146. doi:10.1007/BF00115644

[4] D. Bagchi, D. K. Das, R. M. Engelman, M. R. Prasad and R. Subramanian, "Polymorphonuclear Leukocytes as Poten-tial Source of Free Radicals in the ischemic-Reperfused Myocardium," European Heart Journal, Vol. 11, 1990, pp. 800-813.

[5] D. K. Das, "Intracellular Signaling Mechanisms in Delayed Preconditioning," In: G. Baxter, D. Yellon, Eds., Delayed Preconditioning and Adaptive Cardioprotection, Kluwer Academic Publishers, Dordrecht, 1998, pp. 91103.

[6] S. Renaud and M. De Lorgeril, "Wine, Alcohol, Platelets and the French Paradox for Coronary Heart Disease," The Lancet, Vol. 339, No. 8808, 1992, pp. 1523-1526. doi:10.1016/0140-6736(92)91277-F

[7] D. Bagchi, C. K. Sen, S. D. Ray, D. K. Das, M. Bagchi, H. G. Preuss and J. A. Vinson," Molecular Mechanisms of Cardioprotection by a Novel Grape Seed Proanthocyanidin Extract," Mutation Research, Vols. 523-524, 2003, pp. 87-97. doi:10.1016/S0027-5107(02)00324-X

[8] B. Halliwel, J. M. Gutteridge, C. E. Cross, "Free Radicals, Antioxidants, and Human Disease: Where Are We Now," The Journal of Laboratory and Clinical Medicine, Vol. 199, No. 6, 1992, pp. 598-620.

[9] K. Prasad and J. Kalra, "Oxygen free radicals and Hypercholesterolemic Atherosclerosis: Effect of Vitamin E," American Heart Journal, Vol. 125, No. 4, 1993, pp. 958-973. doi:10.1016/0002-8703(93)90102-F

[10] G. Ruberto, A. Renda, C. Daquino, V. Amico, C. Spatafora, C. Tringali and N. De Tommasi, "Polyphenol Constituents and Antioxidant Activity of Grape Pomace Extracts from Five Sicilian Red Grape Cultivars," Food Chemistry, Vol. 100, No. 1, 2007, pp. 203-210. doi:10.1016/j.foodchem.2005.09.041

[11] J. W. Parry, L. Su, J. Moore, Z. Cheng, M. Luther, R. Jaladanki, J.-Y. Wang and L. Yu, "Chemical Compositions, Antioxidative Capacities, and Anti-proliferative Activities of Selected Fruit Seed Flours," Journal of Agriculture and Food Chemistry, Vol. 54, No. 11, 2006, pp. 3773-3778. doi:10.1021/jf060325k

[12] S. Mertens-Talcott, S. Percival and S. Talcott, "Extracts from Red Muscadine and Cabernet Sauvignon Wines Induce Cell Death in MOLT-4 Human Leukemia Cells," Food Chemistry, Vol. 108, No. 1, 2008, pp. 824-832. doi:10.1016/i.foodchem.2007.11.037

[13] V. Nandakumar, T. Singh and S. Katiyar, "Multi-Targeted Prevention and Therapy of Cancer by Proanthocyanidins," Cancer Letters, Vol. 269, No. 2, 2008, pp. 378-387. doi:10.1016/j.canlet.2008.03.049

[14] H. Hu and Y. M. Qin, "Grape Seed Proanthocyanidin Extract Induced Mitochondria-Associated Apoptosis in Human Acute Myeloid Leukaemia 14.3D10 Cells," China Medical Journal, Vol. 119, 2006, pp. 417-421.

[15] C. Agarwal, R. Singh and R. Agarwal, "Grape Seed Extract Induced Apoptotic Death of Human Prostate Carcinoma DU145 cells via Caspases Activation Accompanied by Dissipation of Mitochondrial Membrane Potential and Cytochrome C Release," Carcinogenesis, Vol. 23, No. 11, 2002, pp. 1869-1876. doi:10.1093/carcin/23.11.1869

[16] X. Ye, R. L. Krohn, W. Liu, S. S. Joshi, C. A. Kuszynski and T. R. McGinn, "The Cytotoxic Effects of a Novel IH636 Grape Seed Proanthocyanidin Extract on Cultured Human Cancer Cells," Molecular and Cellular Biochemistry, Vol. 196, No. 1-2, 1999, pp. 99-108. doi:10.1023/A:1006926414683

[17] J. Zhao, J. Wang, Y. Chen and R. Agarwal, "Anti-Tumor Promoting Activity of a Polyphenolic Fraction Isolated from Grape Seeds in the Mouse Skin Two-Stage Initiation-Promotion Protocol and Identification of Procyanidin B5-3'-gallate as the Most Effective Antioxidant Constituent," Carcinogenesis, Vol. 20, No. 9, 1999, pp. 1737-1745. doi:10.1093/carcin/20.9.1737

[18] J. Belleville, "The French Paradox: Possible Involvement of Ethanol in the Protective Effect against Cardiovascular Diseases," Nutrition, Vol. 18, No. 2, 2002, pp. 173-177. doi:10.1016/S0899-9007(01)00721-3

[19] A. Y. Sun, A. Simonyi and G. Y. Sun, "The 'French Paradox' and Beyond: Neuroprotective Effects of Polyphenols," Free Radical Biology and Medicine, Vol. 32, No. 4, 2002, pp. 314-318. doi:10.1016/S0891-5849(01)00803-6

[20] World Health Organization, "Cancer," February 2006.

[21] T. Hudson, D. Hartle, S. Hursting, N. Nunez, T. Wang, H. Young, P. Arany and J. Green, "Inhibition of Prostate Cancer Growth by Muscadine Grape Skin Extract and Resveratrol through Distinct Mechanisms," Cancer Research, Vol. 67, 2007, pp. 8396-8405. doi:10.1158/0008-5472.CAN-06-4069

[22] M. Neuhouser, "Dietary Flavonoids and Cancer Risk: Evidence from Human Population Studies," Nutrition and Cancer, Vol. 50, No. 1, 2004, pp. 1-7. doi:10.1207/s15327914nc5001 1

[23] P. Harkonen and S. Makela, "Role of Estrogens in Development of Prostate Cancer," The Journal of Steroid Biochemistry and Molecular Biology, Vol. 92, No. 4, 2004, pp. 297-305. doi:10.1016/j.jsbmb.2004.10.016

[24] K. Ozasa, M. Nakao, Y. Watanabe, K. Hayashi, T. Miki, K. Mikami, M. Mori, i F. Sakuch, M. Washio, Y. Ito, K. Suzuki, K. Wakai and A. Tamakoshi, "Serum Phytoestrogens and Prostate Cancer Risk in a Nested Case-Control Study among Japanese Men," Cancer Sciences, Vol. 
95, No. 1,2004 , pp. $65-71$. doi:10.1111/j.1349-7006.2004.tb03172.x

[25] M. G. Hertog, P. C. Hollman, M. B. Katan and D. Kromhout, "Intake of Potentially Anticarcinogenic Flavonoids and Their Determinants in Adults in the Netherlands," $\mathrm{Nu}$ trition and Cancer, Vol. 20, No. 1, 1993, pp. 21-29. doi:10.1080/01635589309514267

[26] S. Kono, M. Ikeda, S. Tokudome and M. Kuratsune, "A Case-Control Study of Gastric Cancer and Diet in Northern Kyushu, Japan," Japan Journal of Cancer Research, Vol. 79, 1988, pp. 1067-1074.

[27] Y. T. Gao, J. K. McLaughlin, W. J. Blot, B. T. Ji, A. Dai and J. F. Fraumeni, "Reduced Risk of Esophageal Cancer Associated With Green Tea Consumption," Journal of the National Cancer Institution, Vol. 86, No. 11, 1994, pp. 855-858. doi: $10.1093 /$ jnci/86.11.855

[28] L. H. Kushi, T. Byers, C. Doyle, E. V. Bandera, M. McCullough, A. McTiernan, T. Gansler, K. S. Andrews and M. J. Thun, "American Cancer Society Nutrition and Physical Activity Guidelines Advisory Committee. American Cancer Society Guidelines on Nutrition and Physical Activity for Cancer Prevention: Reducing the Risk of Cancer with Healthy Food Choices and Physical Activity," A Cancer Journal for Clinicians, Vol. 56, No. 5, 2006, pp. 254-281. doi:10.3322/canjclin.56.5.254

[29] M. Kaur, R. P. Singh, M. Gu, R. Agarwal and C. Agarwal, "Grape Seed Extract Inhibits in Vitro and in Vivo Growth of Human Colorectal Carcinoma Cells," Clinical Cancer Research, Vol. 12, 2006, pp. 6194-6202. doi:10.1158/1078-0432.CCR-06-1465

[30] A. Tyagi, R. Agarwal and C. Agarwal, "Grape Seed Extract Inhibits EGF-Induced and Constitutively Active Mitogenic Signaling but Activates JNK in Human Prostate Carcinoma DU145 Cells: Possible Role in Antiproliferation and Apoptosis," Oncogene, Vol. 22, 2003, pp. 1302-1316. doi:10.1038/sj.onc. 1206265

[31] H. Nomoto, M. Iigo, H. Hamada, S. Kojima and H. Tsuda, "Chemoprevention of Colorectal Cancer by Grape Seed Proanthocyanidin Is Accompanied by a Decrease in Proliferation and Increase in Apoptosis," Nutrition and Cancer, Vol. 49, No. 1, 2004, pp. 81-88. doi:10.1207/s15327914nc4901_11

[32] C. J. Sherr and J. M. Roberts, "CDK Inhibitors: Positive and Negative Regulators of G1-Phase Progression," Genes and Development, Vol. 13, 1999, pp. 1501-1512. doi:10.1101/gad.13.12.1501

[33] J. Moore, Z. Hao, K. Zhou, M. Luther, J. Costa and L. Yu, "Carotenoid, Tocopherol, Phenolic Acid, and Antioxidant Properties of Maryland-Grown Soft Wheat," Journal of Agriculture and Food Chemistry, Vol. 53, No. 17, 2005, pp. 6649-6657. doi:10.1021/jf050481b

[34] Z. Cheng, J. Moore and L. Yu, "High-Throughput Relative DPPH Radical Scavenging Capacity Assay," Journal of Agriculture and Food Chemistry, Vol. 54, No. 20, 2006, pp. 7429-7436. doi:10.1021/jf0611668

[35] K. Zhou, L. Su and L. Yu, "Phytochemicals and Antioxidant Properties in Wheat Bran," Journal of Agriculture and Food Chemistry, Vol. 52, No. 20, 2004, pp. 61086114. doi:10.1021/jf049214g
[36] N. Miller and C. Rice-Evans, "Factors Influencing the Antioxidant Activity Determined by the ABTS Radical Cation Assay," Free Radical Research, Vol. 26, No. 3, 1997, pp. 195-199. doi:10.3109/10715769709097799

[37] K. Wolfe and R. Liu, "Structure-Activity Relationships of Flavonoids in the Cellular Antioxidant Activity Assay," Journal of Agriculture and Food Chemistry, Vol. 56, No. 18, 2008, pp. 8404-8411. doi:10.1021/jf8013074

[38] H. Yoon and R. Liu, "Effect of Selected Phytochemicals and Apple Extracts on NF- $\kappa \mathrm{B}$ Activation in Human Breast Cancer MCF-7 Cells," Journal of Agriculture and Food Chemistry, Vol. 55, No. 8, 2007, pp. 3167-3173. doi:10.1021/jf0632379

[39] K. Wolfe and R. Liu, "Cellular Antioxidant Activity (CAA) Assay for Assessing Antioxidants, Foods, and Dietary Supplements," Journal of Agriculture and Food Chemistry, Vol. 55, No. 22, 2007, pp. 8896-8901. doi:10.1021/jf0715166

[40] L. Yu, S. Haley, J. Perret and M. Harris, "Antioxidant Properties of Extracts from Hard Winter Wheat," Food Chemistry, Vol. 78, No. 4, 2002, pp. 457-461. doi:10.1016/S0308-8146(02)00156-5

[41] L. Yu, D. Adams and M. Gabel, "Conjugated Linoleic Acid Isomers Differ in Their Free Radical Scavenging Properties," Journal of Agricultural and Food Chemistry, Vol. 50, No. 4, 2002, pp. 4135-4140. doi:10.1021/jf020086a

[42] A. Llobera and J. Cañellas, "Antioxidant Activity and Dietary Fibre of Prensal Blanc White Grape (Vitis vinifera) by-Products," International journal of Food Science and Technology, Vol. 43, No. 11, 2008, pp. 1953-1959. doi:10.1111/j.1365-2621.2008.01798.x

[43] J. W. Parry, L. Su, M. Luther, K. Zhou, M. Yurawecz, P. Whittaker and L. Yu, "Fatty Acid Composition and Antioxidant Properties of Cold-Pressed Marionberry, Boysenberry, Red Raspberry, and Blueberry Seed Oils," Journal of Agriculture and Food Chemistry, Vol. 53, No. 3, 2005, pp. 566-573. doi:10.1021/jf048615t

[44] A.-M. Engelbrecht, M. Mattheyse, B. Ellis, B. Loos, et al., "Proanthocyanidin from Grape Seeds Inactivates the PI3-Kinase/PKB Pathway and Induces Apoptosis in a Colon CanceR Cell Line," Cancer Letters, Vol. 258, No. 1, 2007, pp. 144-153. doi:10.1016/j.canlet.2007.08.020

[45] L. M. de Campos, F. V. Leimann, R. C. Pedrosa and S. R. Ferreira, "Free Radical Scavenging of Grape Pomace from Cabernet Sauvignon (Vitis vinifera)," Bioresource Technology, Vol. 99, 2008, pp. 8413-8420. doi:10.1016/j.biortech.2008.02.058

[46] M. G. Massanet, J. A. Montiel, E. Pando and F. L. Rodriguez, "Estudio de Subproductos Agricolas II. Composicion en Acidos Grasos del Aceite de Semilla de uva Palomino," Grasas Aceites, Vol. 37, 1986, pp. 233-236.

[47] M. A. Abou Rayan, A. A. Abdel-Nabey, O. R. Abou Samaha and M. Mohamed, "Characteristics and Composition of Grape Seed Oil," Alexon Journal of Agriculture Research, Vol. 43, 1998, pp. 67-79. 